\title{
Short Technical Report Use of Adenovirus Vectors for Functional Gene Analysis in the Chicken Chorioallantoic Membrane
}

BioTechniques 34:178-183 (January 2003)

\author{
Klaus Schughart and Nathalie \\ Accart \\ Transgene S.A., Strasbourg, \\ France
}

\begin{abstract}
The chicken chorioallantoic membrane (CAM) assay represents one of the most widely used in vivo screening assay for genes with angiogenic (blood vessel-inducing) or angiostatic (inhibition of vessel formation or their destruction) activities. Here we show that adenovirus gene transfer vectors infect cells in the CAM and lead to expression of the viral transgene. Furthermore, infection with an adenovirus vector containing the human vascular endothelial growth factor gene induced the formation of new blood vessels. This improved method saves a considerable amount of time in the identification of genes that can influence blood vessel formation because the expensive and time-consuming production and purification of recombinant protein can be omitted.
\end{abstract}

\section{INTRODUCTION}

For therapeutic treatment of cancer and ischemia, genes and gene products with angiostatic or angiogenic activities are of great interest. Since the growth of tumors is highly dependent on the formation of new vessels, genes exhibiting a negative effect on vessel formation or their stability are considered as promising anticancer therapeutics (7). Several angiostatic genes have been identified, several of which are currently being evaluated in clinical trials for cancer therapy $(2,5)$. Further- more, candidate angiogenic genes are being tested in clinical trials for their potential to induce vessel formation in patients with cardiac or peripheral ischemia $(5,6)$.

Therefore, assays that allow the rapid functional screening of genes for their negative or positive effects on vessel formation have become of great importance. Among the different in vivo assays, the chicken CAM is most widely used. It represents a rapid and easy to handle in vivo system, manipulations are not very expensive (no animal facility is required), and it allows observations in situ over time through a window in the eggshell $(10,16)$. The CAM assay is primarily used for qualitative screening purposes, but several authors have described adaptations for quantitative measurements $(1,13,22)$.

The main disadvantages of the classical CAM assay is that about $250 \mathrm{ng}$ of recombinant protein are required, necessitating a medium-scale production and purification of the protein of interest $(1,15,18,22,23)$. To circumvent this expensive and time-consuming screening, we investigated the use of viral transfer vectors for gene delivery, expression, and subsequent functional analysis.

Here we show that recombinant human adenovirus type 5 (Ad5) gene transfer vectors can infect cells in the chicken CAM, direct expression of the encoded transgene vascular endothelial growth factor $(V E G F)$, and induce the formation of new blood vessels. This improved technology represents an important shortcut in the discovery process toward the identification of new genes with angiogenic or angiostatic activities.

\section{MATERIAL AND METHODS}

\section{Adenovirus Vectors}

The adenovirus vector AdTG14682 contained the bacterial $L a c Z$ gene under the control of the IE1-CMV promoter, a chimeric rabbit betal-globin ivs $2 / \mathrm{IgG}$ intron and the simian virus 40 (SV40) poly(A) signal. Adenovirus vector Ad-RSV-LZ contained the bacterial $L a c Z$ gene fused to a nuclear localization signal (NLS) under the control of the Rous sarcoma virus (RSV) promoter (21). The empty adenovirus vector AdTG6401 consisted only of the vector backbone, deleted in the $\mathrm{E} 1$ and E3 region and without a transgene. Adenovirus vector AdTG15201 contained the human VEGF-165 gene (VEGFA gene isoform 165) under the control of the IE1-CMV promoter, a chimeric rabbit beta1-globin ivs $2 / \mathrm{IgG}$ intron, and the bovine growth hormone poly(A) signal. All viral vectors represent first-generation vectors deleted in the E1 and E3 region (12). Viral doses were expressed as infectious units (IU), as determined in a cell infection assay.

For infections of the CAM, the appropriate amount of an adenovirus vector stock was added on ice to a Matrigel ${ }^{\circledR}$ solution (growth factor depleted; BD Biosciences, San Jose, CA, USA) using a maximum volume of $2 \mu \mathrm{L}$ virus solution per $10 \mu \mathrm{L}$ mixture. Ten microliters of the Matrigel/virus mixture were then added onto a sterilized $3 \times 3$ $\mathrm{mm}$ nylon mesh (pore size $300 \mu \mathrm{m}$ ) (Sefar Nitex ${ }^{\circledR}$ 03-300/51; Polylabo, Strasbourg, France), which was placed on a piece of Parafilm ${ }^{\circledR}$. The complete mixture was then incubated in a humid- 
ified chamber for $30 \mathrm{~min}$ at $37^{\circ} \mathrm{C}$ to allow gel formation.

\section{CAM Assays}

Fertilized White Leghorn chicken eggs (Lohmann Tierzucht, Cuxhaven, Germany) were incubated in a humidified chamber at $37^{\circ} \mathrm{C}$. At day 4 of incubation, a window was cut into the eggshell and the underlying skin and sealed again with an adhesive plaster. At day 10 of incubation, the nylon mesh support containing the Matrigel/ adenovirus mixture was placed onto the CAM. A quarter piece of a sterilized plastic cover slide (13 $\mathrm{mm}$ diameter) (Thermanox ${ }^{\circledR}$; Merck-Eurolab, Fontnay-sous-Bois, France) was then placed on top of the Matrigel/mesh to avoid drying the gel during the following incubation of the eggs at $37^{\circ} \mathrm{C}$. At the indicated time points, the CAM was fixed in situ for 5-10 min with 2\% formaldehyde in PBS. Subsequently, the area of the CAM around the mesh was cut out and placed into a culture dish filled with PBS. Pictures of the CAM vasculature were taken using a dissection microscope. For $\mathrm{LaCZ}$ expression analysis, the dissected CAM was stained overnight as previously described (20), washed twice in PBS, and then photographed using a dissection microscope. For histological sections, the tissues were dehydrated, embedded in paraffin (Histoplast ${ }^{\circledR}$; Life Science International, Eragny, France), and cut into $5 \mu \mathrm{m}$ sections. For the visualization of newly formed blood vessels, tissues were counterstained with hematoxylin and eosin (Merck, Darmstadt, Germany), mounted in Eukitt (Labonord, Villeneuve d'Ascq, France), and then photographed under a light microscope (Nikon, Melville, NY, USA). For LacZ expression analysis, sections were not counterstained but embedded directly in Eukitt and photographed using a light microscope with Nomarski polarization filter optics (Nikon). Immunodetection of Von Willebrand factor (VWF) as a marker for endothelial cells was performed on $5 \mu \mathrm{m}$ paraffin sections by incubation with a primary rabbit anti-human VWF antibody (dilution 1/200; Dako, Glostrup, Denmark), followed by a secondary goat anti-rabbit IgG-dextran polymer-HRP antibody (Dako). HRP activity was revealed with diaminobenzadine (Dako), slides were counterstained with Hematoxylin Harris ${ }^{\circledR}$ (Sigma, St. Louis, USA), and mounted in Mowiol ${ }^{\circledR}$ (Calbiochem-Novabiochem, La Jolla, CA, USA).

\section{RESULTS}

\section{Human Ad5 Vectors Infect the Chicken CAM and Direct Expression of the LacZ Transgene}

The recombinant adenovirus vector AdTG14682 encoding the bacterial $\mathrm{LacZ}$ gene was included into a Matrigel/nylon mesh support and then applied to the chicken CAM on day 10 of incubation. The CAM was prepared at $1,2,3$, and 7 days after infection and stained for the expression of the $\mathrm{LacZ}$ reporter (Figure 1).

LacZ-expressing blue cells were detectable at all time points in the area of the mesh and surrounding tissues (Figure $1, \mathrm{~A}-\mathrm{D})$, whereas in CAMs infected with the empty adenovirus vector AdTG6401, only background staining was observed (Figure 1F).

At day 1 after infection, blue cells can already be seen in the mesh region (Figure 1A). At day 2, the number of positive cells increased, and cells adjacent to the mesh expressed the reporter gene (Figure 1B). At day 3, the staining pattern was similar to day 2 but with more positive cells, especially around the mesh (Figure 1, C and D). Until day 3 , only weak background staining was detected in CAMs infected with empty adenovirus (Figure 1F). This nonspecific staining was clearly distinguishable from the specific reporter genemediated staining because it was less intense and did not exhibit the specific punctuated vector-mediated staining.

At day 7, reporter gene-expressing cells were still detectable in and around the mesh area (data not shown), but at this stage, background staining became more intense, making it difficult to evaluate precisely the area and number of cells exhibiting specific staining.

The localized distribution of the blue cells indicates that the adenovirus, when delivered by a Matrigel/nylon support, was confined to the gel matrix 


\section{DRUG DISCOVERY}

AND GENOMIC TECHNOLOGIES

and cover slide and did not spread further over the CAM surface. Most of the blue cells were located underneath, inside, or in the immediate neighborhood of the mesh (Figure 1, B-D). In addition, single blue cells were observed at some distance from the mesh but still underneath or immediately adjacent to the cover slide (Figure 1, B-D).

Histological sections of positive tissues located adjacent to the mesh revealed that only the outer ectodermal layer of the CAM expressed the $\mathrm{LacZ}$ reporter gene (Figure 1E). For histological sections, Ad-RSV-LZ vector was used because it directs the $\mathrm{LacZ}$ reporter gene product into the nucleus, allowing one to unambiguously distinguish specific adenovirus vectormediated expression from background staining.

\section{Ad5 Vector Expressing the Human VEGF Gene Induced Blood Vessel Formation}

Adenovirus vector carrying the human $V E G F$ gene induced the formation of new blood vessels in the CAM, whereas empty adenovirus and Ad$L a c Z$ vectors had no effect (Figure 2).

Four days after the application of the $V E G F$-containing vector AdTG15201 to the CAM, the induction of new vessels could readily be observed with a dose of $2 \times 10^{7}, 5 \times 10^{7}$, or $1 \times 10^{8} \mathrm{IU}$ (Figure 2, C-F). The two highest doses led to a more dense and regionally extended neo-vascularization. Furthermore, at day 3 , the formation of new vessels was already detectable in situ through the window in the eggshell with the two higher doses of $5 \times 10^{7}$ or $1 \times$ $10^{8} \mathrm{IU}$ but was not obvious with $2 \times 10^{7}$ IU (data not shown). When a lower dose $\left(1 \times 10^{6} \mathrm{IU}\right)$ of the adenovirus $V E G F$ vector was used, no induction of blood vessels was observed (Figure 2B).

The formation of blood vessels was strongest in the immediate neighborhood of the mesh. In some cases, the effect extended to slightly more distant regions but was still confined to the limits of the overlaying cover slide. These observations correlate well with the expression data observed for the $L a c Z$ reporter gene. No vessel formation was observed with the empty adenovirus vectors at all doses tested: $1 \times$
$10^{6}, 2 \times 10^{7}, 5 \times 10^{7}$, and $1 \times 10^{8} \mathrm{IU}$ (Figure 2, A and G, for $5 \times 10^{7} \mathrm{IU}$ ).

In histological sections, we observed the formation of a very dense vascular network around the mesh (Figure 2, H and I). Newly formed vessels were mainly confined to stromal regions directly adjacent to the ectodermal layer of the CAM. In addition, in regions with increased vascularization, the CAM appeared to be thicker than in control embryos or areas more distant from the mesh. In CAMs infected with the empty adenovirus, no reaction or only a weak reaction of the CAM was observed (Figure 2G).
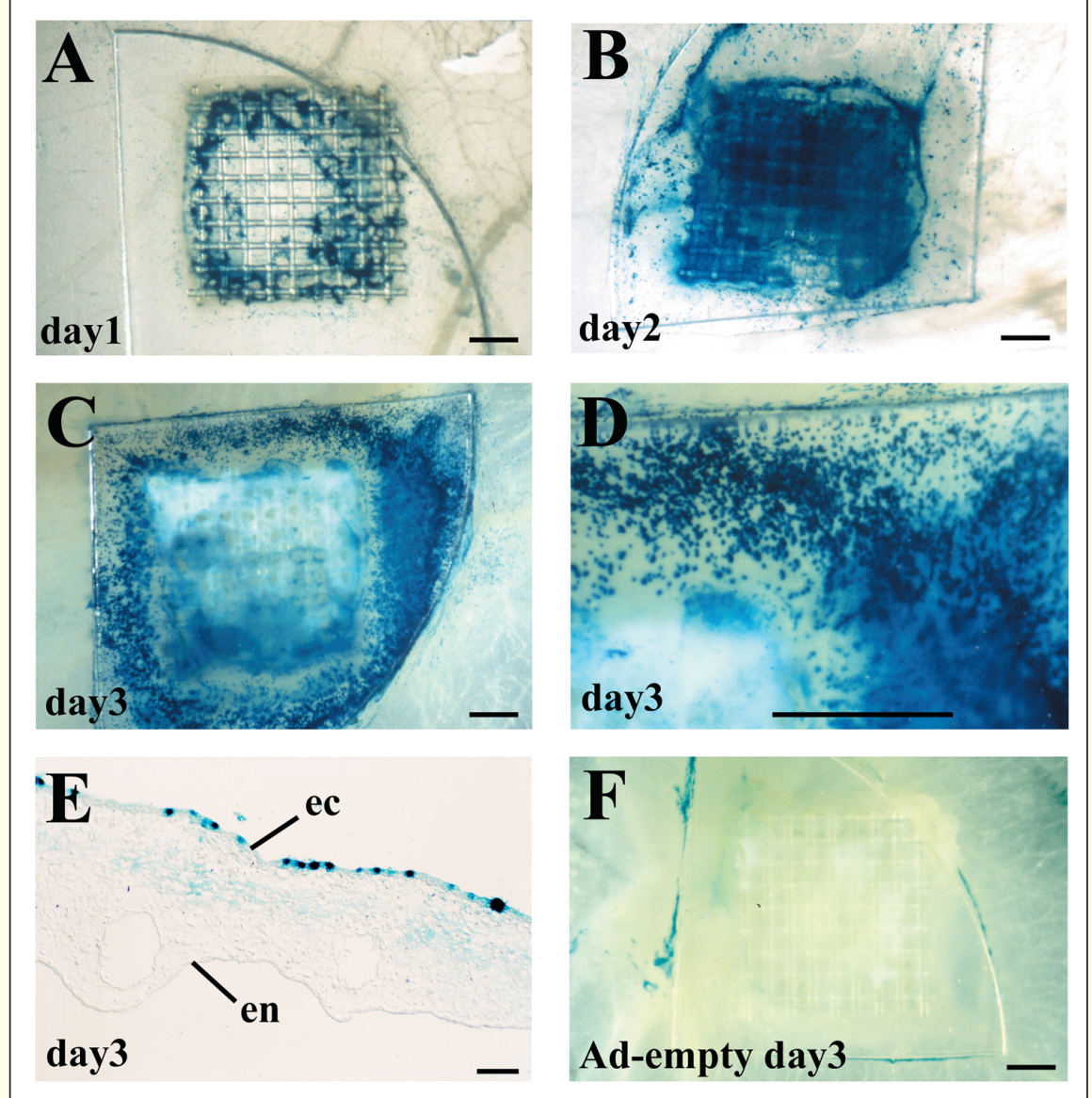

Figure 1. Expression of $L a c Z$ reporter gene in the chicken CAM after infection with recombinant Ad-LZ virus. Chicken CAMs were infected with adenovirus vectors AdTG14682 containing the LacZ gene (A-D) or the empty adenovirus control vector AdTG6401 (F) at a dose of $2 \times 10^{8} \mathrm{IU}$ per CAM. At various times after infection, CAMs were isolated and stained with X-gal for the expression of the $L a c Z$ reporter gene. Positive blue cells could already be detected at day 1 after infection (A). The number of expressing cells increased at day 2 (B) and day 3 (C and D). Panel D shows a higher magnification of panel C. Some weak homogenous blue background staining was observed in a few CAMs infected with the empty adenovirus vector on day $3(\mathrm{~F})$, whereas most embryos infected with the empty vector did not show any background staining. In histological sections of CAMs infected with the Ad-NLS-LZ virus ( 2 $\times 10^{7} \mathrm{IU}$ per CAM), LacZ-positive cells were found in the nuclei of cells in the outer epidermal layer of the CAM (E). ec, ectodermal layer; en, endodermal layer. Measuring bars correspond to $1 \mathrm{~mm}$ in (A-D and $\mathrm{F}$ ) and to $20 \mu \mathrm{m}$ in $\mathrm{E}$. 
can thus conclude that, under the conditions used in these assays, Ad5-mediated gene expression continues for at least six days. When recombinant VEGF protein was applied to the CAM, protein was no longer detectable after four days (23). Thus, using an adenovirus as expression vector will allow a more extended presence of the gene product, which may be important for gene products that give a weaker response or need to be present for an extended period to induce a biological response.

At the later time points, specific expression of the LacZ reporter gene was more difficult to evaluate because background staining increased strongly on day 7 . This background staining may be due to endogenous expression of the chicken $\beta$-galactosidase gene or to changes in the property of the CAM or Matrigel, causing the nonspecific conversion of the X-gal substrate.

We showed that a human Ad5 gene transfer vector can infect chicken em- bryo cells in the CAM. Previous work also demonstrated that cells in the developing heart or central nervous system (CNS) express the reporter gene after systemic or neural tube injection of adenovirus vectors in chicken embryos (8). To date, the exact mechanism of infection in chicken is unknown. Since it is currently unknown whether the chicken genome contains a coxsackie and adenovirus receptor $(C A R)$ gene homologue or where it might be expressed, infection of CAM cells may occur through the $\mathrm{CAR} /$ integrin binding pathway or through integrin binding alone.

It has been shown that the CAR protein represents the primary receptormediating cell type specific infection by the Ad5 virus (11). By performing a protein BLAST search, we could not find a chicken $C A R$ orthologue among the known chicken genes in the GenBank $^{\circledR}$ database. On the other hand, a $C A R$ orthologue has been identified in fish (GenBank), which indicates that the ancestral gene was already present in the early vertebrate lineage. One may thus assume the presence of a $C A R$ gene in chicken.

After binding to the CAR receptor, human Ad5 will involve a secondary receptor for cell entry, the $\alpha_{V} \beta_{3}$ and $\alpha_{V} \beta_{5}$ integrins (11). Since integrins are expressed on most cells, Ad5 exhibits a broad host tropism and can even infect cells that express low levels of CAR; although in this case, a higher multiplicity of infection is needed. In the chicken genome, orthologues of the $\alpha_{\mathrm{V}}$ and $\beta_{3}$ integrin genes can be found (GenBank).

The virus did not spread far on the CAM when it was applied in a Matrigel support. LacZ-positive cells were only detected in the immediate neighborhood of the Matrigel/nylon mesh. Furthermore, we observed that only cells in the outer, ectodermal layer of the CAM expressed the $L a c Z$ gene. Thus, it appears that only those cells that are physically accessible to the virus become in- 


\title{
DRUG DISCOVERY
}

\author{
AND GENOMIC TECHNOLOGIES
}

fected and express the transgene.

Similarly, the effect of the VEGF protein did not extend far beyond the area where $L a c Z$ expression was seen. Also, induced neo-vessels were only observed in stromal regions adjacent to the ectoderm. Thus, it is very likely that the VEGF concentrations necessary for the induction of new blood vessels are obtained only in the immediate neighborhood of infected cells or that local receptors and/or scavengers limit the effect and/or diffusion of the secreted VEGF protein.
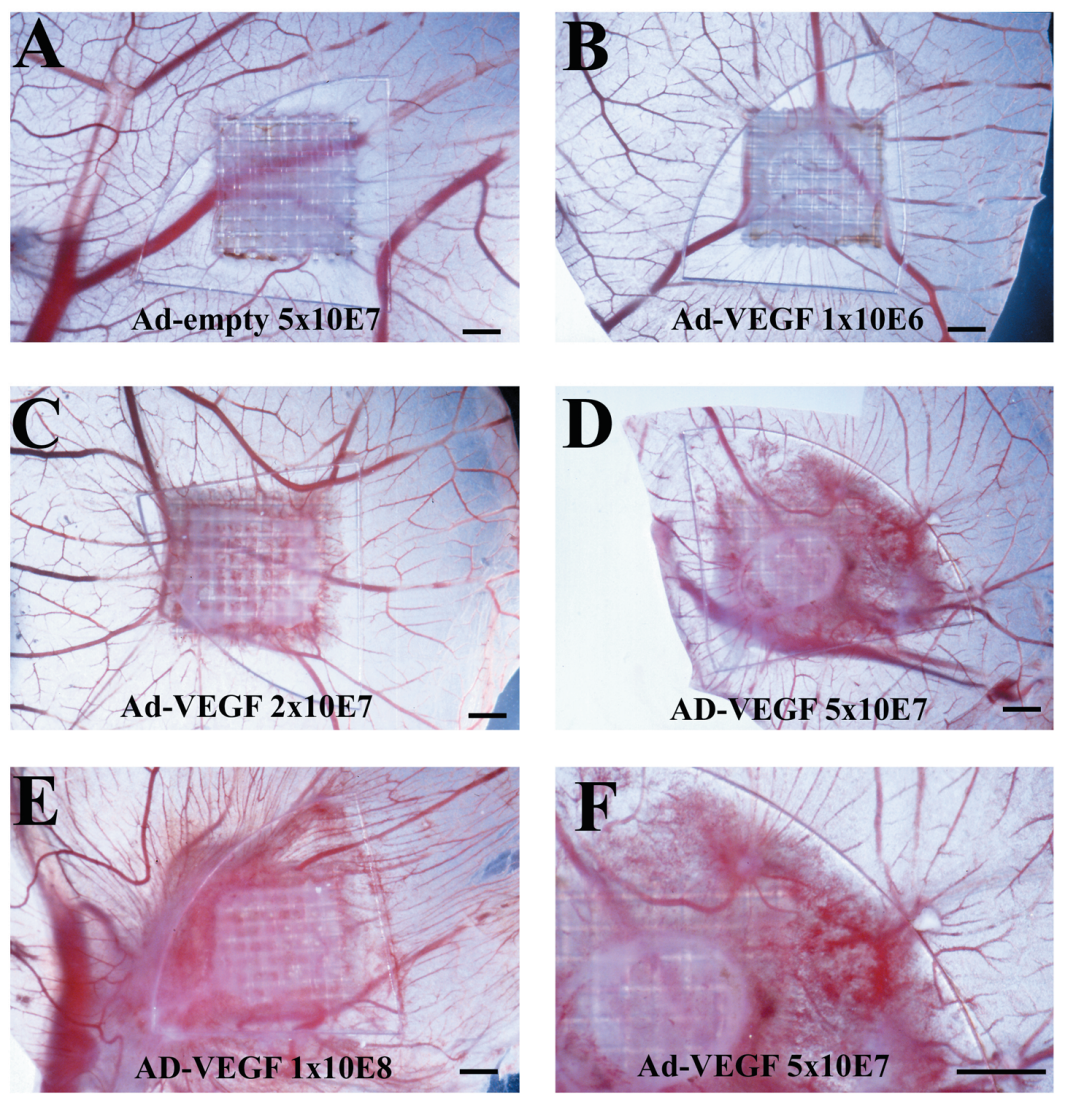

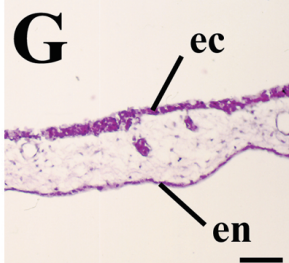

Ad-empty 5x10E7

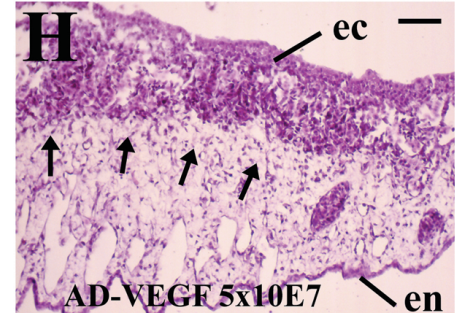

en

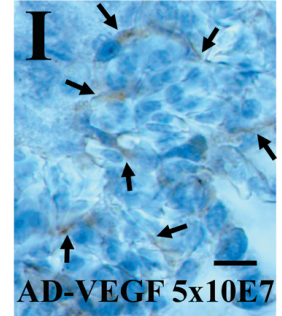

Figure 2. Blood vessel induction in the chicken CAM after infection with the Ad-VEGF virus. Chicken CAMs were infected with recombinant adenovirus vector AdTG15201 containing the human $V E G F$ gene at various doses (B-F and $\mathrm{H}$ ) or the empty adenovirus vector AdTG6401 (A and G) at different doses and analyzed four days later. The empty adenovirus at a dose of $5 \times 10^{7}(\mathrm{~A})$ and the AdVEGF virus at a dose of $1 \times 10^{6} \mathrm{IU}$ (B) did not induce the formation of new blood vessels. At a dose of 2 $\times 10^{7}$, some newly formed blood vessels were observed after infection with the Ad-VEGF virus (C), whereas at the higher doses (D: $5 \times 10^{7} \mathrm{IU} ; \mathrm{E}$ and F: $1 \times 10^{8} \mathrm{IU}$ ), a strong inducing effect was evident. Panel F shows a higher magnification of panel D. In histological sections, the formation of a dense vascular network is observed in Ad-VEGF-infected CAMs $(\mathrm{H})$ on day 4 with $5 \times 10^{7} \mathrm{IU}$ but not in CAMs infected with the empty vector $(\mathrm{G})$. Endothelial cells in CAMs infected with Ad-VEGF virus were revealed by immunostaining with an antibody against VWF (panel I, arrows) Measuring bars correspond to $1 \mathrm{~mm}$ in panel A-F; $20 \mu \mathrm{m}$ in panels $\mathrm{G}$ and $\mathrm{H}$; and $5 \mu \mathrm{m}$ in panel $\mathrm{I}$.
Although vessel formation was visible at day 3 after the infection of the CAM with the Ad-VEGF virus and at a dose of $2 \times 10^{7}$, it is recommended to screen with increasing doses to at least up to $5 \times 10^{7} \mathrm{IU}$ and to perform the final evaluation at day 4 . We did not test later time points. It is possible that the effects may even become more pronounced, especially when using lower doses.

Here expression of a human gene gave rise to a biological response in chicken. Similarly, several other laboratories demonstrated that the human recombinant VEGF is able to induce vessel formation in the chicken CAM $(9,17,22,23)$ and to bind to the chicken VEGF receptor 2 (4). This may be due to the high sequence conservation between the human and chicken VEGF: $72 \%$ identity and $91 \%$ similarity at the amino acid level. However, one should take into consideration that in other cases, the human gene may be less well conserved to cause a biological effect. This could then be circumvented by expressing the chicken orthologue, which can be achieved fast and easily using the recombinant adenovirus vector system (3).

When recombinant protein is used in chicken CAM assays, about 250 ng protein are needed to observe a clear effect of vessel growth $(1,15,18,22,23)$. With our system, $5 \times 10^{7} \mathrm{IU}$ of an adenovirus vector gave a similar response. Since adenovirus vectors can be easily produced in quantities of up to $10^{11} \mathrm{IU}$, this system allows one to perform a large number of assays. In addition, the preparation of an adenovirus vector by homologous recombination (3) will be much faster than expressing and purifying large amounts of recombinant protein.

Another advantage is that adenovirus-transferred genes are expressed directly in CAM cells. Therefore, it will be possible to study the effects of intracellular or membrane-bound gene products. Furthermore, potential posttranslational modifications are also expected to occur in this system. The adenovirus vector system would allow the expression of more than one gene in the CAM by using appropriate bi-cistronic expression cassettes or infecting with a mixture of recombinant viruses. Even complete genomic regions of genes may be incorporated in gutless aden- 
ovirus vectors (19), allowing the expression of splice variants from a given gene locus.

Recently, the use of lentiviral vectors has been described for gene transfer to the chicken CAM (14). Lentiviral vectors have the advantage that infected cells stably express the transgene, but compared to recombinant adenovirus vectors, they are much more difficult to produce in large enough quantities for routine assays.

The system described here should also allow for the study of the inhibitory or stimulatory effects of small chemical molecules or candidate genes that may influence the activity the human VEGF pathway. In this scenario, one would first express the human gene by supplying the appropriate adenovirus vector and then add the chemical substances or apply both together with the Matrigel matrix.

In conclusion, the described experimental system provides an easy and efficient assay system that considerably accelerates the search for genes capable of inducing or repressing the formation of blood vessels. Furthermore, in appropriate experimental settings, the system may allow for the analysis and identification of genes repressing blood vessel formation.

\section{ACKNOWLEDGMENTS}

The Ad-RSV-LZ vector was a gift from L. Stratford-Perricaudet, and the Ad-VEGF virus AdTG15201 was generated by Valerie Calenda (Transgene). We would like to thank Drs. Monika Lusky, Ulla Rasmussen, and Valerie Calenda for providing the stocks of recombinant adenoviruses. We thank Jörg Wilting (University of Freiburg) for introducing K.S. to the CAM technique and for his valuable advice.

\section{REFERENCES}

1.Cao, R., H.L. Wu, N. Veitonmaki, P. Linden, J. Farnebo, G.Y. Shi, and Y. Cao. 1999. Suppression of angiogenesis and tumor growth by the inhibitor K1-5 generated by plasmin-mediated proteolysis. Proc. Natl. Acad. Sci. USA 96:5728-5733.

2.Carmeliet, P. and R.K. Jain. 2000. Angiogenesis in cancer and other diseases. Nature 407:249-257.
3.Chartier, C., E. Degryse, M. Gantzer, A. Dieterle, A. Pavirani, and M. Mehtali. 1996. Efficient generation of recombinant adenovirus vectors by homologous recombination in Escherichia coli. J. Virol. 70:4805-4810.

4.Eichmann, A., C. Corbel, V. Nataf, P. Vaigot, C. Breant, and N.M. Le Douarin. 1997. Ligand-dependent development of the endothelial and hemopoietic lineages from embryonic mesodermal cells expressing vascular endothelial growth factor receptor 2. Proc. Natl. Acad. Sci. USA 94:5141-5146.

5.Ferrara, N. and K. Alitalo. 1999. Clinical applications of angiogenic growth factors and their inhibitors. Nat. Med. 5:1359-1364.

6.Ferrara, N. 2000. VEGF: an update on biological and therapeutic aspects. Curr. Opin. Biotechnol. 11:617-624.

7.Folkman, J. 1971. Tumor angiogenesis: therapeutic implications. N. Engl. J. Med. 285:1182-1186.

8.Griscelli, F., P. Gilardi-Hebenstreit, N. Hanania, W.M. Franz, P. Opolon, M. Perricaudet, and T. Ragot. 1998. Heart-specific targeting of $\beta$-galactosidase by the ventriclespecific cardiac myosin light chain 2 promoter using adenovirus vectors. Hum. Gene Ther. 9:1919-1928.

9.Iruela-Arispe, M.L., M. Lombardo, H.C Krutzsch, J. Lawler, and D.D. Roberts. 1999. Inhibition of angiogenesis by thrombospondin- 1 is mediated by 2 independent regions within the type 1 repeats. Circulation 100:1423-1431.

10.Jain, R.K., K. Schlenger, M. Hockel, and F. Yuan. 1997. Quantitative angiogenesis assays: progress and problems. Nat. Med. 3:1203-1208.

11.Krasnykh, V.N., J.T. Douglas, and V.W. van Beusechem. 2000. Genetic targeting of adenoviral vectors. Mol. Ther. 1:391-405.

12.Lusky, M., M. Christ, K. Rittner, A. Dieterle, D. Dreyer, B. Mourot, H. Schultz, F. Stoeckel, et al. 1998. In vitro and in vivo biology of recombinant adenovirus vectors with E1, E1/E2A, or E1/E4 deleted. J. Virol. 72:2022-2032.

13.Nguyen, M., Y. Shing, and J. Folkman. 1994. Quantitation of angiogenesis and antiangiogenesis in the chick embryo chorioallantoic membrane. Microvasc. Res. 47:31-40.

14.Pfeifer, A., T. Kessler, S. Silletti, D.A. Cheresh, and I.M. Verma. 2000. Suppression of angiogenesis by lentiviral delivery of PEX. A noncatalytic fragment of matrix metalloprotease 2. Proc. Natl. Acad. Sci. USA 97:12227-12232.

15.Ribatti, D., C. Urbinati, B. Nico, M. Rusnati, L. Roncali, and M. Presta. 1995. Endogenous basic fibroblast growth factor is implicated in the vascularization of the chick embryo chorioallantoic membrane. Dev. Biol. 170:39-49.

16.Ribatti, D., A. Vacca, L. Roncali, and F. Dammacco. 2000. The chick embryo chorioallantoic membrane as a model for in vivo research on anti-angiogenesis. Curr. Pharm. Biotechnol. 1:73-82.

17.Ribatti, D., B. Nico, L. Morbidelli, S. Donnini, M. Ziche, A. Vacca, L. Roncali, and M. Presta. 2001. Cell-mediated delivery of fibroblast growth factor-2 and vascular en- dothelial growth factor onto the chick chorioallantoic membrane: endothelial fenestration and angiogenesis. J. Vasc. Res. 38:389397.

18.Salcedo, R., H.A. Young, M.L. Ponce, J.M. Ward, H.K. Kleinman, W.J. Murphy, and J.J. Oppenheim. 2001. Eotaxin (CCL11) induces in vivo angiogenic responses by human CCR3+ endothelial cells. J. Immunol. 166:7571-7578.

19.Schiedner, G., N. Morral, R.J. Parks, Y. Wu, S.C. Koopmans, C. Langston, F.L. Graham, A.L. Beaudet, et al. 1998. Genomic DNA transfer with a high capacity adenovirus vector results in improved in vivo gene expression and decreased toxicity. 18:180183

20.Schughart, K., R. Bischoff, U.B. Rasmussen, D.A. Hadji, F. Perraud, N. Accart, O. Boussif, N. Silvestre, et al. 1999. Solvoplex: a new type of synthetic vector for intrapulmonary gene delivery. Hum. Gene Ther. 10:2891-2905.

21.Stratford-Perricaudet, L.D., I. Makeh, M. Perricaudet, and P. Briand. 1992. Widespread long-term gene transfer to mouse skeletal muscles and heart. J. Clin. Invest. 90:626-630.

22.Vazquez, F., G. Hastings, M.A. Ortega, T.F. Lane, S. Oikemus, M. Lombardo, and M.L. Iruela-Arispe. 1999. METH-1, a human ortholog of ADAMTS-1, and METH-2 are members of a new family of proteins with angio-inhibitory activity. J. Biol. Chem. 274:23349-23357.

23.Wilting, J., B. Christ, M. Bokeloh, and H.A. Weich. 1993. In vivo effects of vascular endothelial growth factor on the chicken chorioallantoic membrane. Cell Tissue Res. 274:163-172.

Received 25 July 2002; accepted 3 October 2002.

\section{Address correspondence to:}

Dr. Klaus Schughart

GBF, German Research Center for Biotechnology Mascheroder Weg 1

D-38124 Braunschweig, Germany

e-mail:kls@gbf.de 